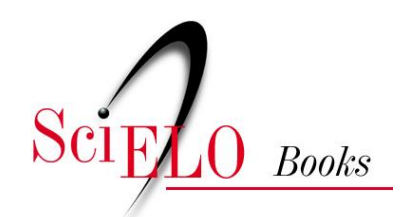

\title{
Do modernismo paulista ao regionalismo do nordeste
}

\author{
Cid Seixas Fraga Filho
}

\section{SciELO Books / SciELO Livros / SciELO Libros}

FRAGA FILHO, CS. Do modernismo paulista ao regionalismo do nordeste. In: SWARNAKAR, S., FIGUEIREDO, ELL., and GERMANO, PG., orgs. Nova leitura crítica de Jorge Amado [online]. Campina Grande: EDUEPB, 2014, pp. 60-71. ISBN 978-85-7879-328-9. Available from SciELO Books $<$ http://books.scielo.org $>$.

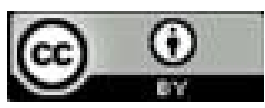

All the contents of this work, except where otherwise noted, is licensed under a Creative Commons Attribution $\underline{4.0 \text { International license. }}$

Todo o conteúdo deste trabalho, exceto quando houver ressalva, é publicado sob a licença Creative Commons Atribição 4.0.

Todo el contenido de esta obra, excepto donde se indique lo contrario, está bajo licencia de la licencia $\underline{\text { Creative }}$ Commons Reconocimento 4.0. 


\title{
Do Modernismo Paulista ao Regionalismo do Nordeste
}

\author{
Cid Seixas FragaFilho
}

A partir de 1928, com a guinada telúrica dos modernistas de 22, o Nordeste, até então refratário às novidades europeizantes da Semana de Arte Moderna, encontra uma possível identidade entre as suas embrionárias vertentes de modernidade literária e as propostas "futuristas" e modernistas capitaneadas pela nova metrópole econômica do país.

Seguindo, inconscientemente, o exemplo pioneiro de Gilberto Freyre, em Pernambuco, Jorge Amado e outros jovens intelectuais da província inserem a Bahia no quadro do pensamento artístico e social do Século XX. Posturas contrárias aos gritos histriônicos da paulicéia desvairada eram vistas como forma de atraso cultural do Nordeste, enquanto os escritores dessa região brasileira perseveravam na gestação de uma nova consciência crítica que explodiria dois anos depois, com o chamado Romance de 30.

Enquanto a arte concebida pelos jovens do centro metropolitano construía sua identidade a partir do alimento antropofágico digerido na Europa, os jovens da "roça" tiravam da terra as raízes com que se alimentavam. Mesmo em São Paulo, um intelectual como Monteiro Lobato adotou, pioneiramente, postura similar a que viria a caracterizar a literatura nordestina, sendo de pronto execrado pela vaia juvenil 
e visto como um passadista. Tais fatos - que daqui a dez anos serão anciões centenários (quando a Semana de 22 completará um século) - exigem um reexame com olhos do hoje.

Em fevereiro de 2022 o Brasil estará celebrando a aventurosa eclosão da Semana de Arte Moderna, nome pomposo para os três dias de eventos realizados no Teatro Municipal de São Paulo. Artes plásticas, literatura e música foram os temas centrais das discussões e performances distribuídas na segunda-feira, dia 13, na quarta, dia 15, e na sexta-feira, dia 17 de fevereiro de 1922. Espera-se que, no bojo do centenário, sejam vistos e compreendidos os fatos que, ao longo do século XX, ganharam um estatuto mítico capaz de enublar tudo aquilo que não representasse uma aceitação passiva e contritamente religiosa dos feitos e fatos traquinados pelos seus corifeus.

O espírito de corpo dos chamados modernistas conduzia um rolo compressor capaz de esmagar, como uma camada de lama, a todos aqueles que não demonstrassem uma aceitação incondicional ao pensamento "novo". Todos conhecem o estigma imposto pelos "vanguardistas" ao "passadista" Monteiro Lobato. Como o furacão da botocúndia derrubou os cavaletes da exposição de Anita Malfatti, conjeturada por Lobato como paranóia ou mistificação, os pontasde-lança do modernismo conseguiram, por algum tempo e em vários contextos, esvanecer o esplendente vendaval com que Lobato enriqueceu a cultura brasileira, desenterrando os tesouros escondidos no mato e nas ruas obscuras. As idéias 
do Jeca Tatu, ironicamente esboçadas por Monteiro Lobato como proposta de construção da identidade nacional, não foram percebidas num momento em que o Brasil buscava uma fisionomia européia.

É verdade que a partir de 1928 o modernismo brasileiro passou a merecer este adjetivo brasileiro, mas o fosso estava cavado e dividia profundamente os territórios da arte. Convém lembrar que Oswald de Andrade, passados os embates da chamada fase destrutiva do modernismo, mostrou o significativo fato de Urupês ser anterior a Pau Brasil e à obra de Gilberto Freyre. Reconhecia, assim, o valor e a consistência do pensamento de Monteiro Lobato, aproximando a guinada de 28 do pioneirismo do velho amotinado de Taubaté, com a seguinte confissão: "nós também trazíamos nas nossas canções, por debaixo do futurismo, a dolência e a revolta da terra brasileira.” (ANDRADE, 1971, p.4).

O episódio constituído pela crítica de Lobato à pintora Anita Malfatti, publicada em dezembro de 1917, oito dias após a abertura da exposição, demorou para ser superado, especialmente pela declarada opção do autor pela arte clássica e pela crença na sua permanente e irretocável perfeição. Contraditoriamente ao que ele realizou como escritor e como intelectual sensível à cultura brasileira, no famigerado artigo cometeu um equívoco "passadista" ao pontificar: "Todas as artes são regidas por princípios imutáveis, leis fundamentais que não dependem da latitude nem do clima." (LOBATO, 1917/1967, p.60). 
Ao tempo em que argüia ferozmente a adesão de Anita às vanguardas européias, o escritor exaltava seu talento e suas qualidades. No pensamento crítico de Monteiro Lobato estava fortemente embutida a proposta de construção de uma estética brasileira independente, livre de qualquer herança colonial que represente perda de identidade. Daí a intolerância que causou ressentimentos.

O caso Monteiro Lobato é, para nós, paradigmático porque antecipa uma perspectiva artística similar que fez com que o modernismo do nordeste só eclodisse plenamente - ou só fosse percebido como tal - com o romance regionalista de 30. As manifestações anteriores, por terem sido confundidas como contrárias à modernidade "desvairada", não foram assimiladas pela historiografia literária brasileira.

O modernismo paulista figura na memória nacional como um inexcedível núcleo do pensamento de vanguarda, excluindo de modo maniqueísta toda e qualquer oposição aos seus trejeitos, sob a pecha de passadismo. Por isso, convém equilibrar a balança assinalando que ele corresponde a um momento da história do país dominado pela chamada "política café com leite". As oligarquias e as elites quatrocentonas produziram seu contraveneno, representado pelas manifestações de rebeldia estética da Semana de Arte Moderna. Criouse toda uma mitologia de apanágio ao Modernismo do centro econômico do país, anulando qualquer significado possível a ser atribuído à construção da modernidade artística em outras regiões do país. Na Bahia, por exemplo, nós, bem intencion- 
dos intelectuais de província, fomos responsáveis por interpretar os avanços e recuos do pensamento artístico da década de vinte como a mais enfadonha forma de conservadorismo.

Como se sabe, a própria dinâmica social produz, em qualquer parte, seus mecanismos de conservação das estruturas envelhecidas e de irrupção das novas formas. Tanto no Nordeste patriarcal quanto no Centro Sul capitalista os padrões estéticos europeus mais tradicionais constituíam moeda de grande valor. A substituição automática das formas emboloradas, anteriormente trazidas da Europa, por todo e qualquer grito de rebeldia que atravessasse o Atlântico era a grande tentação dos jovens artistas brasileiros. Tanto lá, no Centro Sul, quanto cá, no Nordeste, o atraso com relação à modernidade européia era um fato sensível. As duas regiões do país reagiram de modo diverso e de acordo com fatores culturais distintos. Ao contrário do que afirmou Lobato em 1917 - contrariando o que demonstra sua obra - as artes não são regidas por princípios imutáveis, nem por leis fundamentais que não dependem da latitude nem do clima. As artes são parcialmente condicionadas antes que possam obedecer a princípios imutáveis. A grande metrópole econômica do país é marcada, para o bem e para o mal, por uma realidade diversa daquela constituída em outras latitudes.

É desse modo que a obra de Jorge Amado desenvolve, de forma conseqüente e definida, uma vertente identitária da nacionalidade destinada a substituir a figura do índio, idealizada por Alencar, por outros atores, incluindo a mistura 
de sangues dos diversos cantos do mundo. Desde os árabes, que aqui chegaram para mercar suas quinquilharias, até os africanos trazidos em porões de aviltantes navios. Assim tem lugar de relevo na obra amadiana, o negro real e palpável que conseguiu afirmar a sua cultura, a despeito do aniquilamento do sujeito propiciado pela escravidão. Centrando a noção de valor de um povo mestiço para além da história oficial, Amado realiza desde Tenda dos Milagres (obra que explicita as questões levantadas com exemplar picardia desde quando despiu a camisa-de-força do Partido Comunista), até a madura construção de obras como Tocaia grande e O sumiço da santa.

Desconstruir a herança colonial européia e fortalecer a auto-estima da gente mestiça - ou do povo brasileiro - é o que Jorge Amado começou a fazer, a partir dos anos 70, por entre as frestas da história contada e por entre as festas dos sentidos incendiados na tempestade do texto. O apimentado, o gorduroso e o farto uso de frutos africanos, ao contrário de diminuir o valor da obra amadiana, como queria uma prestigiada vertente da crítica universitária, vieram a se impor como elementos definidores de um valor identitário já simbolizado nas coisas da cozinha por Gilberto Freire.

Quando o escritor traça seu próprio caminho, muitos estudiosos de formação socialista passam a ver Jorge Amado como uma espécie de desertor da causa do proletariado. Depois de aderir, com fervor juvenil e sem nenhuma crítica, aos princípios do realismo socialista, ele se deixa tomar pelo desencanto e do desencontro que se apoderaram da 
esquerda após a necrose do totalitarismo stalinista. Os crimes do autoritarismo foram expostos aos olhos do mundo e, nesse balanço de perdas e ganhos, houve quem descobrisse que os fins não justificam os meios.

Outros, no entanto, continuaram impermeáveis ao senso do lugar comum: os fins não justificam. Mas continuaram usando todos os meios para chegar aos fins sonhados.

Considerado este quadro, por que os anos sessenta trouxeram a negação do valor da obra amadiana? Até a metade do século, o arrebatamento pelo seu texto era quase unânime, vindo, em seguida, um gradativo obscurecimento crítico. Nos anos setenta, esta obra conheceu verdadeiro massacre, tanto do ponto de vista político quanto cultural. No Brasil, a exemplo do que ocorreu nos Estados Unidos, setores envolvidos com questões raciais apontaram a valorização da mestiçagem no universo de Jorge Amado como mistura impura, ou como apagamento da pureza racial negra. (ÊEpa, rei! Este filme já passou em algum lugar. E deu no que não deu.)

De um lado e do outro, o mito da pureza étnica gera segregações. Não é exagero afirmar que a obra de Jorge Amado chegou a ser rejeitada por duas razões contrárias: de um lado, os feitores da pureza africana desconfiavam da construção romanesca de uma civilização negro-mestiça (vendo na mestiçagem o embranquecimento); do outro lado, arianos e quase-brancos não toleravam a elevação do negro e do mestiço à categoria mítica de herói incondicional (vendo na exaltação da mestiçagem a apologia de raças até então ocupantes 
de espaços exclusivamente periféricos).

A valorização de uma mitologia crioula pela obra amadiana punha em pé de igualdade velhos mitos europeus e novos mitos afro-brasileiros. Valores, quer sejam politicamente corretos ou não, machistas, patriarcais, ou desconstrutores do estabelecido - valores integrantes dos costumes crioulos da Bahia - constituíram a isto que chamo de "mitologia crioula" da obra amadiana.

Sabemos que a cultura impõe preceitos e preconceitos, mutáveis em vários tempos. Se, hoje, a academia revaloriza a obra de Jorge Amado, convém lembrar que, há dez ou vinte anos atrás, os cursos de Literatura das universidades baianas, seu lugar de origem, não dedicavam nenhuma disciplina ao estudo dos livros do maior contador de histórias da raça brasileira.

Hoje, estudos de gênero admitem observar o lugar da mulher nos romances de Jorge Amado, estudos étnicos percorrem a construção do orgulho negro e mestiço, estudos culturais encontram importantes estratégias de descolonização do pensamento.

Mas por que a obra desse contador de histórias da civilização mestiça atravessou turbulências e calmarias, quedas e baixas na bolsa de valores da crítica da cultura?

Uma hipótese é que isso decorre do fato de Jorge Amado ter sido, de início, um fiel tradutor dos princípios e mandamentos do marxismo soviético, para em seguida abandoná-los em favor do flerte mais aberto com os festins da 
pequena burguesia. Se o romancista dos primeiros livros escrevia para comunista nenhum botar defeito, ao se desligar das imposições do Partido, ele experimentou a liberdade absoluta de criar, renunciando inclusive ao princípio segundo o qual a literatura deve pôr em primeiro plano a sua função de construtora e forma do conhecimento. Livre para criar, Amado procura a antítese da obra engajada: a literatura feita para divertir.

Por entre o riso solto e a narrativa de aparência meramente anedótica, o romancista produz o melhor da sua obra, ocultando e entremostrando, velando e revelando o compromisso social por entre as dobras de um tecido alegre. Do discurso marcado pelo cumprimento de tarefas partidárias, evoluiu para um discurso pleno de sentidos, armadilhas, sugestões e arremedilhos.

Ora, o leitor habituado ao romance de tese, onde a mensagem política sobrepujava o jogo do prazer, veria o novo figurino amadiano com a mesma suspeita dirigida à figura intelectual do ex-comunista. Deixar o Partido por discordar das suas práticas era um fato considerado equivalente à traição aos seus princípios. Daí a metralhadora giratória do patrulhamento ter varrido a obra de Jorge Amado, estimulando-o a aprofundar o distanciamento com as práticas ditadas pela estética marxista dos anos de ferro.

Voltando ao título aqui proposto, podemos concluir que as diferenças entre o modernismo paulista e a olvidada modernidade nordestina permitiram não só a fixação dos tra- 
ços mais nítidos do Romance de 30 quando de obras como a de Jorge Amado, cujos cem anos o Brasil e o mundo agora comemoram, em eventos como este.

Este trabalho surge pelo honroso convite da doutora Sudha Swarnakar para proferir a palestra de abertura do Colóquio JORGE INTERNACIONALMENTE AMADO, na Universidade Estadual da Paraíba. Embora conhecesse a professora Sudha através do seu trabalho desenvolvido no Brasil, foi através do doutor Humberto Oliveira que tive oportunidade de conhecer - lhe e vir a participar desse evento.

\section{Referências}

ALENCAR, José de. Como e porque sou romancista: autobiografia literária em forma de carta. Porto Alegre: Mercado Aberto, 1998.

ALVES, Ívia. Arco \& flexa: Contribuição para o estudo do modernismo. Salvador: Fundação Cultural do Estado da Bahia, 1978.

AMADO, Jorge. Tereza Batista cansada de guerra. Rio de Janeiro: Record, 1972.

AMADO, Jorge. Tocaia grande: a face obscura. Rio de Janeiro: Record, 1984. 
AMADO, Jorge. O sumiço da santa. Rio de Janeiro: Record, 1988.

AMADO, Jorge. Navegação de cabotagem: apontamentos para um livro de memórias que jamais escreverei. Rio de Janeiro: Record, 1992.

ANDRADE, Oswald de. Ponta de lança. 2. ed. Rio de Janeiro: Civilização Brasileira, 1971.

ARCO \& FLEXA: edição fac-similar. revista literária de 1928/1929, Salvador, Fundação Cultural do Estado da Bahia, 1978. (n 1, 66 p., n., 2/3, 70 p., n. 4/5. 90 p.).

CANDIDO, Antonio. Literatura e sociedade. 5. ed. São Paulo: Nacional, 1967.

DELLA VOLPE, Galvano. Sociologia. São Paulo: Ática, 1980.

FREYRE,Gilberto. Tempo morto e outros tempos. Rio de Janeiro: J. Olympio, 1975.

MONTEIRO LOBATO. Paranóia ou mistificação [Crítica originalmente publicada em dezembro de 1917]. Idéias de Jeca Tatu. São Paulo: Brasiliense, 12. ed. 1967, p.59-65. 
MOTA, Carlos Guilherme. Ideologia da Cultura brasileira. 3. ed. São Paulo: Ática, 1977.

SCHAFF, Adam. História e verdade. São Paulo: Marins Fontes, 1978.

SEIXAS, Cid. Jorge Amado: da guerra dos santos à demolição do eurocentrismo. Salvador: CEDAP, 1993.

SEIXAS, Cid. Modernismo e diversidade: impasses e confrontos de uma vertente regional. Légua $\&$ meia- Revista de literatura e diversidade cultural. Feira de Santana: UEFS, v. 3, n. 2, 2004, p. 52-61.

SEIXAS, Cid. Triste Bahia, oh! Quão dessemelhante. Notas sobre a literatura na Bahia. Salvador: EGBA / Secretaria da Cultura e Turismo, 1996. (Coleção As Letras da Bahia).

SERRA. Ordep. Jorge Amado, sincretismo e candomblé. In —: Águas do rei. Petrópolis: Vozes, 1995, p. 289-360. 